\title{
Agreement Between Rapid Hepatitis B Surface Antigen Test Kit and ELISA for the Diagnosis of Hepatitis B Virus Infection in Gondar, North West Ethiopia.
}

\section{Mulualem Lemma ( $\nabla$ mulualeml@yahoo.com )}

University of Gondar College of Medicine and Health Sciences https://orcid.org/0000-0003-0425-422X

Gueshay Tsegay

Gondar College of Medical Sciences: University of Gondar

Kasaw Adane

University of Gondar College of Medicine and Health Sciences

\section{Research}

Keywords: specificity, sensitivity, positive predictive value, negative predictive value

Posted Date: August 2nd, 2021

DOl: https://doi.org/10.21203/rs.3.rs-656418/v1

License: (c) (1) This work is licensed under a Creative Commons Attribution 4.0 International License.

Read Full License 


\section{Abstract}

Background: Hepatitis B Virus is one of the major causes of global public health problems. Diagnosis of $\mathrm{HBV}$ is done by using ELISA and immune-chromatographic assays for detecting different serologic markers. Hepatitis B surface antigen ( $\mathrm{HBsAg}$ ) is the most frequently used serological marker employed to diagnosis HBV using Rapid Diagnostic Test (RDT) and Enzyme Linked Immunosorbent Assay (ELISA) methods. The RDT method is the most commonly used diagnostic tool in Ethiopia as well as in most African countries. Therefore assessing and knowing the diagnostic performance of the RDT is important.

Method: A prospective cross sectional study was done at University of Gondar comprehensive specialized Hospital from Feb, 2017- May, 2017. Ethical clearance was obtained from School of Biomedical and Laboratory Sciences Research Ethics Committee. Permission was obtained from Blood Bank office to use blood sample collected from voluntary blood donors. HBsAg was diagnosed using RDT and ELISA methods. ELISA considered as gold-standard to the performance of RDT. Data were entered into statistical package for social sciences (SPSS) version 20 software and analysis was done by using SPSS and for sensitivity, specificity, predictive value, and likelihood ratio Medi calc software. The agreement of the methods presented assessed using kappa value.

Result: Each 161 specimen was diagnosed using both ELISA (ADVANCED $®$ ) and RDT (Ecotest $\left.{ }^{\circledR}\right)$. A total ELISA confirmed 41 positive specimens and 120 ELISA confirmed negative specimens were re-analyzed using RDT. The results of RDT showed only 35 positives from the total tested specimens including 29 which already positive by ELISA and RDT showing a sensitivity of $70.7 \%$ and specificity $95 \%$ with its kappa value 0.69 indicating a good agreement with ELISA.

Conclusion and recommendation: Rapid Ecotest ${ }^{\circledR}$ test of HBsAg has good agreement with ELISA but low sensitivity and high false negative value, so there should be an algorithm for HBV diagnostic methods when we used a rapid test kits.

\section{Introduction}

Hepatitis B Virus (HBV) belongs to the family of hepadnaviridae which is a double stranded deoxyribonucleic acid (DNA) enveloped virus (1). The virus particles deliver their

DNA in to the hepatocyte nucleus at the time of infection. The viral DNA is then converted to a covalently closed circular DNA (ccCDNA) that serve as the transcriptional template for pre-genomic ribonucleic acid (RNA) and messenger RNA (mRNA) for hepatitis surface antigen (HBsAg), hepatitis B e antigen / core antigen ( $\mathrm{HBeAg} / \mathrm{HBcAg})$, polymerase, and $X$ protein $(\mathrm{HBx})(2)$.

HBV is one of the major causes of global public health problem, it caused 1.34 million death in the world and affects mostly the African and the western pacific regions (3). The infection develops into acute viral infection and achieves immune clearance yielding a life-long immunity. The chronic carriers of the virus may develop wide range of clinical presentations from the state of asymptomatic carrier with normal liver 
histology to chronic liver diseases such as cirrhosis and hepatocellular carcinoma $(4,5)$. It also induce immune mediated attack of the hepatocytes by cytotoxic $T$ cells which initially produced against the HBsAg and the main causes of the inflammation and necrosis the liver (6).

By country, estimated Hepatitis B surface antigen (HBsAg) sero-prevalence ranges between $5 \%$ and $19 \%$. The total number of carriers may approach 58 million with as many as 12.5 million likely to die prematurely due to hepatitis B-induced liver disease (7). In Ethiopia the prevalence of HB virus in different groups of the society is different. The data showed that, in health professionals $4.52 \%$ (8), in community $8.0 \%$ (9), medical west handler $6.3 \%$ (10) and in diabetes groups $3.7 \%(11)$.

Diagnosis of HBV infection includes detection of different serologic markers on patient's blood by looking for the HBV specific antigens and antibodies. These markers also used to identify different phases of HBV infection and to determine whether a patient has acute or chronic HBV infection. The immune response of $\mathrm{HBV}$ is as the result of prior to infection or vaccination, or is susceptible to infection. Such as HBsAg indicates the presence of active infection, recovery and immunized from HBV Hepatitis B core antibody (HBcAb) appears at the onset of acute infection but may also indicate chronic infection (12). HBsAg is the major viral marker used for the detection of HBV infection (13).

Laboratory Diagnosis of HBV is done by using different techniques. Such as, Enzyme Linked immunosorbent Assay (ELISA), radioimmunoassay (RIA), immune-chromatographic assays (ICA), haema agglutination assays and molecular techniques like Polymerase chain Reaction (PCR), of these, EIAs, RIAs and PCR are the most sensitive methods (14). Utilizing Rapid kit are much more common than other testing techniques in Africa as well in Ethiopia. Our concern is to determine the method agreement of ELISA with that of the rapid test kit, which is mostly available in most of the health facility in our country. For clinical management as well as for intention of vaccination in national level diagnosis of HBV by the proper methods of diagnostic kit is indispensable. Based on this we determine the sensitivity and specificity as well as the level of agreement of the HBV rapid diagnostic kit with ELISA.

\section{Methods And Materials}

\section{Study Design and Setting}

An institutional based a prospective cross sectional study design was conducted form Feb 2017- May 2017 to assess the agreement between rapid Chromatography method and ELISA methods for testing HBsAg from. The study was done in Gondar at University of Gondar comprehensive specialized Hospital in Northwest Ethiopia.

\section{Study participants}

The study participants are these volunteers and signed the consent form for willing of to participate in the study among these blood donors in the blood bank center of Gondar at University of Gondar comprehensive specialized Hospital. The total sample size were 161 and selected by Non-probability 
quota sampling methods. Form these volunteer study participants $5 \mathrm{ml}$ of blood collected parallel to the blood donation process. The plasma was separated as soon as possible after collection and the plasma was refrigerated below - 20 degree centigrade until it processed for the testing process.

\section{LABORATORY ANALYSIS}

\section{ELISA Determination}

ELISA test is done by ADVANCED ${ }^{\circledR}$ ELISA test method. It is double antibody sandwich immunoassay which employs specific anti HBsAg monoclonal antibodies to HBsAg immobilized at the bottom of micro titter wells. And the polyclonal antibody against to HBsAg coupled with horseradish peroxidase (HRP) as a conjugate solution during the assay. The existing HBsAg in the specimen will react with these antibodies to form an "antibody-HBsAg-antibody-HRP" immune complex. After the unbound material is washed off during the assay procedure of washing steps, substrate is applied to indicate the test result. The appearance of blue color in microtiter wells indicates HBsAg reactive result. The absence of the color indicates non-reactive result in the specimen.

\section{Rapid Chromatography determination}

The selected chromatography test is Ecotest ${ }^{\circledR}$ rapid test kit. It is an anti HBsAg immobilized on the test region of the membrane. During testing the specimen reacts with anti HBsAg antibody conjugated to colored particles and pre coated on to the sample pad of the test. The mixture then migrates through membrane by capillary action and interacted with reagents on the membrane. If there is enough HBsAg in the specimen a colored band will form at the test region of the membrane.

\section{Data processing and analysis}

The test result was cleaned and enters to Microsoft excel work sheet and transferred to Statistical Package for Social Sciences (SPSS) version 20.The stat-two way contingency table analysis software was also use to calculate sensitivity, specificity, predictive and kappa values.

\section{Quality control}

To get reliable results for our study, guidelines in collection, handling, processing and storing of samples was used. We use already validated rapid kit (Ecotest $\left.{ }^{\circledR}\right)$ which currently available in our market and ELISA kit (ADVANCED $®$ ) currently used by Gondar blood bank as confirmatory test. All the reagents and materials which are not expired and correctly stored reagents. Procedural control is included in the rapid test, a red line appearing in the control region $(C)$ is the internal quality control it confirming sufficient specimen volume and correct procedural technique. For ELISA, control standards supplied with kit and well tested to confirm the test procedure and verify proper test performance.

\section{Result}


A total of 161 volunteer blood donors were participate on the study. We collect 161 blood sample and the serum used to diagnosed HBV infection using ADVANCED $®$ ELISA test method and Ecotest ${ }^{\circledR}$ rapid test kit method. From theses 161 serum sample of study participants, 41 samples were ELISA confirmed positive and 120 were ELISA confirmed negative specimens. Again we re-analyzed all the 161 serum sample using the rapid chromatography method of Ecotest $\AA^{\circledR}$ rapid test kit. The results showed 35 positives from the total tested serum sample. Form these positive samples of the RDT 29 samples were being already positive by ELISA (Table 01).

The gold standard test for our study is ADVANCED $®$ ELISA diagnosis test. It used for the diagnosis HBV for these blood donation system only not for other issues. But rapid test method is used for clinical diagnosis in hospitals, in the peripheral health facility, private health centers, and for pre-screening of peoples during $\mathrm{HB}$ virus vaccination program. We blindly choose this rapid test kit in the market for this research purpose without having any prior information about the test method.

The test method of Ecotest $\AA^{\circledR}$ showing sensitivity and specificity were $70.7 \%$ and $95 \%$, respectively and $83 \%$ positive predictive value (PPV) and $90.5 \%$ and negative predictive value (NPV) (Table 02). In our study the two diagnosis methods showed good agreement by having the kappa value of $0.69(p<0.001)$.

\section{Discussion}

Hepatitis B virus is very contagious disease in human kind. It is obvious that there should be good rapid test method for HB virus in for the primary health center and serious medical management as well as for the proper control and prevention of the virus. In district and peripheral hospitals, diagnostic methods like ELISA are expensive, time consuming, requires skilled man power and equipped infrastructure. Therefore commercially available rapid test kits for HBV is very fundamental. But most kits in the market are vary in their performance quality. There is a great demand for evaluating the validity of screening methods, with high diagnostic efficiency $(15,16)$.

Our study used ELISA as a confirmatory test because we used ELISA technique for blood donor screening, more advanced techniques and it is less frequently available in our countries. Our ELISA result show consistent with other ELISA test done in blood donors $(17,18)$. Even if the rapid kit showed high false negative result when compared with that of the ELISA because of having low sensitivity but they both method have good agreement. Using the rapid test kit we can screen patients for the clinical management or for knowing there status for vaccination purpose as preliminary reporting test. But for blood screening and transfusion purpose using rapid test kite still very difficult. Because of the test has to be much more sensitive not to miss any reaction. Therefore, like HIV virus screening there should be an algorism of different test kits based on their sensitivity and specificity for the facility that cannot use ELISA methods.

On the other hand, a major concern in using RDT is their variability in degree of sensitivity and specificity. Manufacturer's insert leaflet claim the sensitivity of Ecotest ${ }^{\circledR}$ to be $99.9 \%$ (Assure Tech (Hangzhou) co., Ltd.). The actual performance was found to be only sensitivity about of $71 \%$ sensitivity and $95 \%$ 
specificity. Shows that the sensitivity and positive predictive values of Ecotest ${ }^{\circledR}$ relatively low. On the other hand specificity and NPV of fairly high, this could be one of the quality of the RDT kit that can able to identify specific antigens which is produced by the infected cells and detected in the patient serum. Our finding showed in line with other studies also $(17,19)$.

Other Studies reported that sensitivity of $79 \%$ and specificity was $98.9 \%$ (20), and $100 \%$ sensitivity of rapid test kit with a specificity of $91.7 \%$ for HBsAg (21). Other report also showed $100 \%$ specificity and $93.4 \%$ sensitivity of ELISA to pick up all false negative (22). So our result show low sensitivity than other test methods. Hypothetically rapid test kit should have high sensitivity and allowable specificity to decrease these false positive and false negative results. Our result show $29.3 \%$ false negative and $5 \%$ false positive , which has much more high false negative but in many case of the test kits that have high false positive result are desirable than false negative results. False positive results may have much more chance to be repeated by other test kits or by confirmatory methods but false negative results may one of the source of infection for the community by missing the true cases with in it. Due to the prevalence difference of HBV in different regions, having different genotype variation of HBV in different geographical distribution (23) and different in techniques as well as methods for the development of rapid test kit will play a great role for the development of test kite don't have the similar test accuracy index.

\section{Conclusion And Recommendation}

Generally even if rapid chromatographic test (Ecotest $\left.{ }^{\circledR}\right)$ have a good agreement with ELISA (ADVANCED ${ }^{\circledR}$ ) but it has low sensitivity. For a choice of diagnostic test of HBV for developing countries where there is no facility and other option for doing HBV diagnosis out of rapid test kit. And still very difficult because there may much more true case will be reported as false negative. For proper diagnosis of HBV infection there should be an algorithm for countries in national and regional level to minimize these false negative results in these health facility that don't have ELISA or PCR confirmatory methods.

\section{Abbreviations}

(DNA) Double stranded deoxyribonucleic acid

(HBV) Hepatitis B Virus

(HBsAg) Hepatitis B surface antigen

(ICA)Immune-chromatographic assays

(RDT) Rapid Diagnostic Test

(SPSS) Statistical package for social sciences

(PCR) Polymerase chain Reaction 


\section{Declarations}

\section{Ethics approval and consent to participate}

Ethical clearance was obtained from the research and ethics review committee of School of Biomedical and Laboratory Science, College of medicine and health Sciences, University of Gondar and permission letter obtained from Gondar blood bank center before starting the actual work. The aim of the study was explained for study participants and written consent from obtained from them. Confidentiality was kept by removing any personal identifiers from data and the sample, and keeping the result kept confidentially.

\section{Consent for publication}

Consent for publication is obtained from the study participants after explanation of that the published articles will not include any personal identifier variables.

\section{Availability of data and materials}

All data generated or analyzed during this study are included in this published article (it is found in excel form as supplemented materials)

\section{Funding}

Supported by Department of Immunology and Molecular biology laboratory. College of Medicine and Health Sciences University of Gondar.

\section{Author's contributions}

ML, KA and GT participate in development the protocol and laboratory analysis. ML and KA participate in statically analysis and manuscript development. All the authors red and approved the final manuscripts.

\section{Competing interests}

All authors declare that, they do not have any competing interests.

\section{Acknowledgement}

We would like to acknowledge University of Gondar College of medicine and health science, school of biomedical and laboratory science for ethical approval of the protocol. University Gondar comprehensive specialized hospital and Gondar blood bank center for allowing the work to do and for their facility we used. Finally we would like to acknowledge all the study participants for their unreserved willingness to participate in the study. 


\section{References}

1. Ganem D, Varmus HE. The molecular biology of the hepatitis B viruses. Annual review of biochemistry. 1987;56(1):651-93.

2. Tuttleman JS, Pugh JC, Summers JW. In vitro experimental infection of primary duck hepatocyte cultures with duck hepatitis B virus. Journal of virology. 1986;58(1):17-25.

3. Galel SA, Fontaine MJ, Viele MK, Gonzalez C, Goodnough LT. Transfusion medicine. Wintrobe's Clinical Hematology: Thirteenth Edition. Wolters Kluwer Health Adis (ESP); 2013. pp. 547-86.

4. Lian M, Liu Y, Yu S-Z, Qian G-S, Wan S-G, Dixon KR. Hepatitis B virus x gene and cyanobacterial toxins promote aflatoxin B1-induced hepatotumorigenesis in mice. World Journal of Gastroenterology: WJG. 2006;12(19):3065.

5. Madden CR, Finegold MJ, Slagle BL. Hepatitis B virus X protein acts as a tumor promoter in development of diethylnitrosamine-induced preneoplastic lesions. Journal of virology. 2001;75(8):3851-8.

6. Levinson W. Review of medical microbiology and immunology. McGraw-Hill Education; 2014.

7. Brian C, Sean D, Pharm D, Uchenna I, Pharm D, Kris V. Chronic hepatitis B from a global perspective: Epidemiology and costs of illness. J Clin Gastroenterol. 2004;38(suppl 3):158-68.

8. Gebremariam AA, Tsegaye AT, Shiferaw YF, Reta MM, Getaneh A. Seroprevalence of hepatitis B virus and associated factors among health professionals in University of Gondar Hospital, Northwest Ethiopia. Advances in preventive medicine. 2019;2019.

9. Woldegiorgis AE, Erku W, Medhin G, Berhe N, Legesse M. Community-based sero-prevalence of hepatitis B and C infections in South Omo zone, southern Ethiopia. PloS one. 2019;14(12).

10. Shiferaw $Y$, Abebe T, Mihret A. Hepatitis $B$ virus infection among medical waste handlers in Addis Ababa, Ethiopia. BMC Res Notes. 2011;4(1):479.

11. Mekonnen D, Gebre-Selassie S, Fantaw S, Hunegnaw A, Mihret A. Prevalence of hepatitis B virus in patients with diabetes mellitus: a comparative cross sectional study at Woldiya General Hospital, Ethiopia. Pan African Medical Journal. 2014;17(1).

12. Mast EE, Weinbaum CM, Fiore AE, Alter MJ, Bell BP, Finelli L, et al. A Comprehensive immunization strategy to eliminate transmission of hepatitis B virus infection in the United States;

recommendations of the Advisory Committee on Immunization Practices (ACIP); Immunization of adults; Part II. 2006.

13. Ahn SH. Quantification of HBsAg: basic virology for clinical practice. 2011.

14. Chameera E, Noordeen F, Pandithasundara H, Abeykoon A. Diagnostic efficacy of rapid assays used for the detection of hepatitis B virus surface antigen. Sri Lankan Journal of Infectious Diseases. 2013;3(2).

15. Khan JK, Lone DS, Hameed A, Munim R, Bhatti M, Khattak AA, et al. Evaluation of the performance of two rapid immunochromatographic tests for detection of hepatitis B surface antigen and anti HCV antibodies using ELISA tested samples. Annals of King Edward Medical University. 2010;16(1 SI). 
16. Ekwi D, Fokunang C, Adiogo D, Essame O. Evaluation of Three Rapid Diagnostic Tests for Detection of Hepatitis B Surface Antigens (HBsAg) in Yaounde-Cameroon. HEALTH SCIENCES AND DISEASES. 2013;11(1).

17. Erhabor O, Kwaifa I, Bayawa A, Isaac Z, Dorcas I, Sani I. Comparison of ELISA and rapid screening techniques for the detection of HBsAg among blood donors in Usmanu Danfodiyo university teaching hospital Sokoto, North Western Nigeria. J Blood Lymph. 2014;4(2):124.

18. Saran R. Transfusion medicine: technical manual: Directorate General of Health Services,Ministry of Health and Family \&\#8230.

19. Farooqui MK. Comparison between rapid immuno-chromatographic device test and ELISA in detection of HBsAg and anti-HCV antibodies. International Journal of Recent Scientific Research. 2016;7(2):9129-2132.

20. Raj AA, Subramaniam T, Raghuraman $S$, Abraham P. Evaluation of an indigenously manufactured rapid immunochromatographic test for detection of HBsAg. Indian J Pathol Microbiol. 2001;44(4):413-4.

21. Zahoorullah L. agglutination and immunochromatographic screening tests versus reverse passive hemagglutination for hepatitis B surface antigen in serum. Pak J Med Res. 2001;40(2):69-71.

22. Kaur H, Dhanao J, Oberoi A. Evaluation of rapid kits for detection of HIV, HBsAg and HCV infections. Indian J Med Sci. 2000;54(10):432-4.

23. Consumption WECoPRtA, Organization WH. WHO Expert Committee on Problems Related to Alcohol Consumption: Second Report: World Health Organization; 2007.

\section{Tables}

Table 1: Comparison of Ecotest ${ }^{\circledR}$ RDT test kit and ADVANCED ${ }^{\circledR}$ ELISA diagnosis test used for the diagnosis of HBV at UoGRCSH, June 2017.

\begin{tabular}{lllll} 
& & \multicolumn{2}{c}{ ELISA } & \\
\cline { 3 - 5 } Rapid kit & Positives & 29 & 6 & 35 \\
\cline { 2 - 5 } & Negatives & 12 & 114 & 126 \\
& & & & \\
\hline & Total & 41 & 120 & 161
\end{tabular}

Table 2: Ecotest ${ }^{\circledR}$ RDT test kit performance for diagnosis of HBV with reference to the ADVANCED ${ }^{\circledR}$ ELISA diagnosis at UoGCSH, June 2017. 


\begin{tabular}{llll} 
& \multirow{2}{*}{ Estimated value } & \multicolumn{2}{c}{$95 \%$ confidence interval } \\
\cline { 3 - 4 } & & Lower limit & Upper limit \\
\hline Sensitivity & 0.71 & 0.54 & 0.83 \\
\hline Specificity & 0.95 & 0.89 & 0.98 \\
\hline
\end{tabular}

For any particular positive test result, the probability that it is:

\begin{tabular}{llll}
\hline True positive (PPV) & 0.83 & 0.66 & 0.93 \\
\hline False positive & 0.17 & 0.07 & 0.34 \\
\hline
\end{tabular}

For any particular negative test result, the probability that it is:

\begin{tabular}{llll}
\hline True negative (NPV) & 0.9 & 0.84 & 0.95 \\
\hline False negative & 0.095 & 0.05 & 0.16 \\
\hline Positive likelihood ratio & 14.15 & 6.33 & 31.62 \\
\hline Negative likelihood ratio & 0.31 & 0.19 & 0.496
\end{tabular}

